Document downloaded from:

http://hdl.handle.net/10251/145995

This paper must be cited as:

Gil-Castell, O.; Badia, J.; Ingles-Mascaros, S.; Teruel Juanes, R.; Serra, A.; Ribes-Greus, A. (12-2). Polylactide-based self-reinforced composites biodegradation: Individual and combined influence of temperature, water and compost. Polymer Degradation and Stability. 158:40-51. https://doi.org/10.1016/j.polymdegradstab.2018.10.017

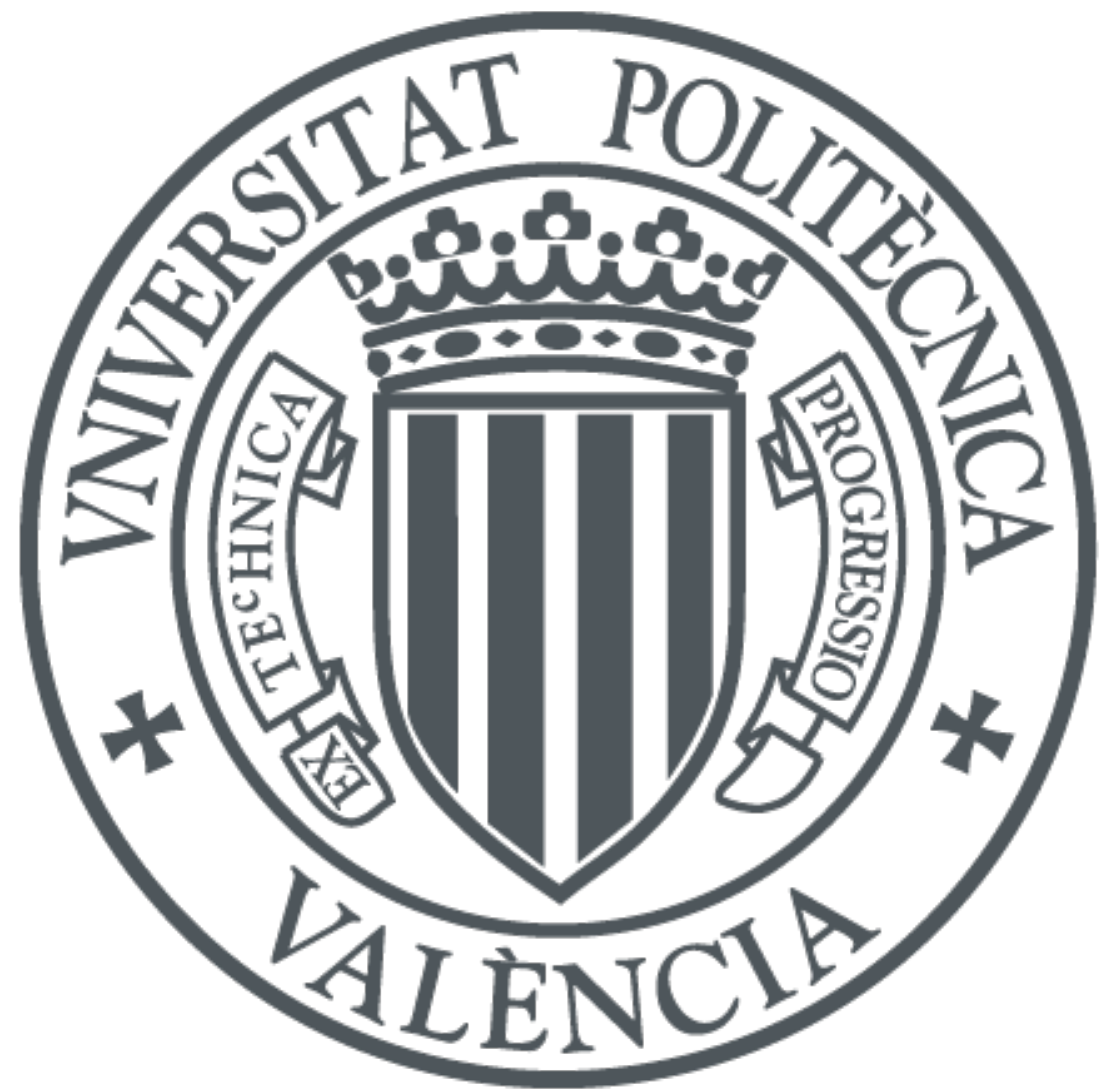

The final publication is available at

https://doi.org/10.1016/j.polymdegradstab.2018.10.017

Copyright Elsevier

Additional Information 


\title{
POLYLACTIDE-BASED SELF-REINFORCED COMPOSITES BIODEGRADATION: INDIVIDUAL AND COMBINED INFLUENCE OF TEMPERATURE, WATER AND COMPOST
}

\author{
O. Gil-Castell, J.D. Badia, S. Ingles-Mascaros, R. Teruel-Juanes, A. Serra, A. \\ Ribes-Greus*
}

\begin{abstract}
Self-reinforced polymer composites (SRCs) are proposed as a suitable alternative for composite development, based in the combination of a polymeric matrix and a polymeric fibre made of the same polymer. SRCs based in polylactide (PLA) could be fully biodegradable and their valorisation routes could presumably be assimilated to those for neat PLA. In this sense, the aim of this study was to develop new self-reinforced PLA-based composites and ascertain their biodegradability. For this purpose, PLA-based SRCs were obtained through a thermocompression procedure and their biodegradability corroborated under standard conditions (ISO 20200). Moreover, a deep study of the effect of the different factors involved in the biodegradation of the composites such as the temperature, the water and the compost medium was considered relevant to delimitate the long-term properties and valorisation routes for these materials. The macroscopic and microscopic appearance as well as the thermo-oxidative stability, the thermal properties and the molar mass were evaluated. Although degradation was perceived due to the effect of temperature, the synergistic combination of water and temperature -and compost- was found to play a key role in the biodegradation of these materials. Overall, these SRCs can be considered as promising candidates, since their end-of-life management options can be guaranteed under standardised composting conditions.
\end{abstract}

\section{Keywords}

Self-reinforced composites (SRCs); polylactide (PLA); biodegradation; composting; hydrothermal degradation; thermal degradation 


\section{Introduction}

Global resources of oil, natural gas and coal are limited. They could be progressively exhausted in a near future and prices would rise [1] which, along with the persistent accumulation of waste, has led to severe environmental policies [2]. Accordingly, petroleum-based commodity plastics may have to be replaced by innovative alternatives. Polymers from renewable resources may become a sustainable solution. Indeed, a lot of research has been published in the last decade in many sectors such as food packaging, agriculture and biomedicine, among others [3].

The study of the long-term properties of polymers from renewable resources, as well as the evaluation of the end-of-life, is still a matter of interest, since it would allow the exploration of new applications for these materials [2]. The combination of process and performance must be efficiently balanced to guarantee a proper service behaviour, along with an appropriate end-oflife management and valorisation into downstreamed products, feedstock, energy and/or their reintegration in the C-cycle through biodegradation in natural environment [4].

Poly(lactic acid), or polylactide (PLA), is one of the most promising thermoplastic biopolymers since it can be obtained from renewable resources, has attractive mechanical properties, low energy required for production, potential biodegradability and highly industrially extended [5][9]. In recent years, the high demand of PLA-based biodegradable products has produced an emergent market in many countries. At the beginning, PLA had a great interest in the medical field, given its good biodegradability and biocompatibility [10], [11]. Nowadays, applications such as films for food packaging, textiles, disposable bottles and pieces in the agriculture or automotive industry have been developed [5], [6]. Some of these novel applications meet new requirements such as high mechanical properties while keeping the intrinsic biodegradability[12], [13].

Polymer composites offer improved mechanical properties by means of the combination of a polymeric matrix and fillers or reinforcements. However, a poor matrix/fibre interfacial adhesion caused by differences of chemical structure, surface energies and properties may limit their applicability [14], [15]. Moreover, the disposal, separation and recycling of these composite materials are some relevant aspects to take into account [16]-[18]. In order to overcome these concerns, self-reinforced composites (SRCs) have been proposed as a suitable alternative for composite development, based in the combination of a polymeric matrix and a polymeric fibre made of the same polymer. If these composites were based on PLA, fully biodegradable composites would be obtained and their recycling could be performed without the need of separation of fibre and matrix [19]-[21]. Moreover, the use of biopolymers such as PLA to fabricate sustainable self-reinforced composites may open the possibility of composting as an alternative to the end-of-life [19]. To date, PLA-based SRCs have been studied to improve their strength and rigidity for clinical uses such as rods screws and plates [22], [23]. Other researchers reported various physical and thermal treatments and their effects on widening the processing window of this material [24]. However, any results have been found with sandwich-like structured SRCs based on PLA.

The aim of this study was to develop new self-reinforced PLA-based composites as well as to validate their biodegradability in standard conditions and assess the additive impact of the different factors involved in their biodegradation, such as the temperature, water and compost. 


\section{Materials and methods}

\subsection{Materials}

Polylactide (PLA) matrix PLA4043D grade (94\% L-lactic acid content) was purchased from Natureworks ${ }^{\circledR}$, with a density of $1.24 \mathrm{~g} \cdot \mathrm{cm}^{-3}$, a glass transition temperature $\left(T_{g}\right)$ in the $65-70{ }^{\circ} \mathrm{C}$ range and a melting temperature $\left(T_{m}\right)$ in the $145-160^{\circ} \mathrm{C}$ range. PLA fibre grade PLACD500 was purchased from Ahlstrom ${ }^{\circledR}$ as non-woven fabrics of extruded/fixed-bonded PLA (spunbond), with a thickness of $180 \mu \mathrm{m}$ and a surface density of $3 \cdot 10^{-3} \mathrm{~g} \cdot \mathrm{cm}^{-2}$. Tetrahydrofuran (THF), $(\geq 99.8 \%)$ used for SEC sample preparation and analysis, was supplied by Sigma-Aldrich ${ }^{\circledR}$ and used without further purification.

\subsection{Preparation of PLA matrix}

The PLA film was processed through drying-extrusion-calender cycles. Drying was performed into a DSN5006HE dehumidifier, extrusion in a single-screw IAQP-LAP E-30/25 (L/D = 25, D $=30 \mathrm{~mm}$ ) and calendering by means of a Premier International Laboratory Calender. Prior to the extrusion process, the pellets were dehumidified in-line at $80{ }^{\circ} \mathrm{C}$ for $4 \mathrm{~h}$. Then, the extrusion and calendering were carried out according to the parameters gathered in Table 1. The temperatures $\mathrm{T}_{1}$ to $\mathrm{T}_{6}$ are the temperatures of each thermally-controlled section of the barrel of the extruder, from the hopper to the die.

Table 1. Extrusion and calendering parameters.

\begin{tabular}{|c|c|c|c|c|c|c|c|c|c|c|c|}
\hline Thopper & $T_{1}$ & $T_{2}$ & $T_{3}$ & $T_{4}$ & $T_{5}$ & $T_{6}$ & $T_{\text {nozzle }}$ & $\begin{array}{c}T_{\text {calender }} \\
\text { rollers }\end{array}$ & $\begin{array}{c}\text { Linear } \\
\text { speed }\end{array}$ & $\begin{array}{c}\text { Rollers' } \\
\text { speed }\end{array}$ & $\begin{array}{l}\text { Average } \\
\text { thickness }\end{array}$ \\
\hline \multicolumn{9}{|c|}{$\left({ }^{\circ} \mathrm{C}\right)$} & $\left(\mathrm{cm} \cdot \mathrm{s}^{-1}\right)$ & (rpm) & $(\mu \mathrm{m})$ \\
\hline 20 & 120 & 160 & 170 & 175 & 175 & 175 & 175 & 45 & 1.5 & 4.1 & 660 \\
\hline
\end{tabular}

\subsection{Preparation of PLA self-reinforced composites}

The PLA self-reinforced composites were prepared by means of thermo-compression in a fouraxis hot plate press. Two different composite dispositions were considered, as shown in Table 2: (i) matrix-fibre-matrix (C2) and (ii) matrix-fibre-matrix-fibre-matrix (C3). Then, in order to ascertain the influence of the matrix on the entire composite, a double (M2) and triple (M3) matrix samples were obtained with the same thickness than that of the composites. The processing temperature was set at $150{ }^{\circ} \mathrm{C}$, between the melting of the fibre $\left(T_{m}=159.17^{\circ} \mathrm{C}\right)$ and the matrix $\left(T_{m}=148.50^{\circ} \mathrm{C}\right)$ to ensure completely wetting of fibres by the matrix. Melting temperatures were obtained by differential scanning calorimetry (DSC) as later described. Accordingly, the press was pre-heated at $150{ }^{\circ} \mathrm{C}$. Then, the $\mathrm{C} 2$ and $\mathrm{C} 3$ composites, processed into 1 and $1.5 \mathrm{~mm}$ thick $10 \times 15 \mathrm{~cm}^{2}$ Teflon ${ }^{\circledR}$ moulds, respectively, were introduced without pressure during $12 \mathrm{~min}$. After that, a compression force of $50 \mathrm{kPa}$ was applied for $2 \mathrm{~min}$ [25]. Then, the composites were cooled down out of the press into the mould system under a pressure of $2.5 \mathrm{kPa}$ to prevent samples from being bent. Finally, the samples were stored into a desiccator for further analyses. 
Table 2. Sample labelling according to disposition of components.

\begin{tabular}{|c|c|c|c|}
\hline Type of sample & Acronym & Disposition & Scheme \\
\hline Fibre & $\mathrm{F}$ & $\mathrm{F}$ & 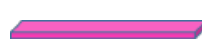 \\
\hline \multirow{3}{*}{ Matrix } & M2 & M-M & \\
\hline & \multirow[b]{2}{*}{ M3 } & \multirow[b]{2}{*}{ M-M-M } & \\
\hline & & & \\
\hline \multirow{3}{*}{ Composite } & $\mathrm{C} 2$ & M-F-M & \\
\hline & \multirow[b]{2}{*}{ C3 } & \multirow[b]{2}{*}{ M-F-M-F-M } & \\
\hline & & & \\
\hline
\end{tabular}

\subsection{Biological degradation}

The biological degradation was studied according to the standard ISO 20200: "Determination of the degree of disintegration of plastic materials under simulated composting conditions in a laboratory" [26]. For this purpose, a solid substrate consisting of synthetic solid residue was prepared. The composition of the substrate was (as dry \%wt): 10\% compost (Verdesol ${ }^{\circledR}$ ), $40 \%$ wood sawdust (J. Adrian ${ }^{\circledR}$ ), 30\% rabbit food (Cunimed ${ }^{\circledR}$ ), 10\% corn starch (Unilever ${ }^{\circledR}$ ), $5 \%$ sucrose $\left(\right.$ Acor $\left.{ }^{\circledR}\right), 4 \% \operatorname{corn}$ oil (Fontasol $\left.{ }^{\circledR}\right)$ and 1\% urea (Bayer Garden $\left.{ }^{\circledR}\right)$. Then, a $55 \%$ wt of distilled water was added to the mixture immediately before the biodisintegration assay. The substrate was checked in terms of volatile solid content (VS), $\mathrm{pH}$ and $\mathrm{C} / \mathrm{N}$ ratio, considering that the percentage of carbon corresponds to half of the VS value, according to the standard [26].

The samples, in duplicates, with dimensions of $25 \times 25 \times 1$ (1.5) $\mathrm{mm}^{3}$ were dried into a vacuum oven at $40 \pm 2{ }^{\circ} \mathrm{C}$ until constant mass. Prior to introducing the samples into the substrate, they were immersed into ultra-pure water for $30 \mathrm{~s}$. The flasks were sealed to avoid excessive evaporation. However, in order to guarantee air exchange, the flasks were perforated with $5 \mathrm{~mm}$ holes in the sides, below the compost level. The aerobic degradation was carried out into a Thermo Scientific Heraeus Function Line incubator with air circulation at a constant temperature of $58 \pm 2{ }^{\circ} \mathrm{C}$ for 90 days. The moisture, mixing and aeration of the samples were periodically controlled according to the standard. The water content of the substrate is known to play a key role, thus affecting to the microbial activity during composting and, subsequently, to the rate of degradation. Since a moisture reduction of the substrate due to the effect of temperature was expected [27], the percentage of water was monitored along the whole process, by adding distilled water when necessary, to maintain the optimal percentage of moisture, as recommended by the standard. After the composting assay, the resultant compost was characterised in terms of their final mass, dry mass, volatile solid content (VS) and $\mathrm{pH}$.

Once finished, the compost was dried at $58 \pm 2{ }^{\circ} \mathrm{C}$ until constant mass and sieved to separate the remaining polymeric pieces greater than $2 \mathrm{~mm}$, as specified in the standard, to calculate the biodisintegration degree $(D)$ by means of the Equation 1,

$$
D(\%)=\frac{M_{i}-M_{f}}{M_{i}} \times 100 \quad \text { Equation } 1
$$

where $M_{i}$ corresponds to the initial dry mass of the sample and $M_{f}$ represents the dry mass of the recovered sample after composting and sieving. 
In order to validate the biodegradation results, the volatile solids reduction $(R)$ was calculated according to the Equation 2,

$$
R(\%)=\frac{\left[m_{i}(D M)_{i}(V S)_{i}\right]-\left[m_{f}(D M)_{f}(V S)_{f}\right]}{\left[m_{i}(D M)_{i}(V S)_{i}\right]} \times 100 \quad \text { Equation } 2
$$

where $m_{i}$ denotes the initial wet mass of the synthetic solid waste, $(D M)_{i}$ is the initial dry mass of the synthetic solid waste, and $(V S)_{i}$ represents the volatile solids of the initial dry synthetic solid waste. The term $m_{f}$ corresponds to the final dry mass of the obtained compost, $(D M)_{f}$ represents the final dry mass of the compost; and $(V S)_{f}$ is the volatile solids value of the obtained compost.

\subsection{Hydrothermal degradation}

The hydrothermal degradation assay was carried out along 180 days. The samples, in duplicates, were introduced into $25 \mathrm{~mL}$ glass vials with screwed PTFE caps, filled with $20 \mathrm{~mL}$ of ultra-pure water. Then, they were introduced into a Thermo Scientific Heraeus Function Line incubator at $58 \pm 2{ }^{\circ} \mathrm{C}$. The samples were removed from the hydrolytic medium at several stages along 15 extractions: one sample per week from month 0 to month 2 , and one sample fortnightly between month 2 to month 6 . After each extraction, the samples were dried with a tissue to remove the water from the surface and then introduced into a vacuum oven Heraeus Vacutherm for $48 \mathrm{~h}$ to remove the remnant humidity. Then, they were introduced into zip bags and stored for further analyses at normalised lab conditions [28].

\subsection{Thermal degradation}

The thermal degradation assay was performed along 180 days. Following the same sample extraction planning than for the hydrothermal degradation test, 15 extractions were considered along the assay: 1 sample per week from month 0 to month 2, and 1 sample fortnightly between month 2 to month 6. Each vacuum dried sample was wrapped in aluminium foil and placed into a closed glass vessel to avoid contact with the ambient humidity. Then, they were placed into a Thermo Scientific Heraeus Function Line incubator at $58 \pm 2^{\circ} \mathrm{C}$. After each extraction, the samples were removed from the oven in duplicates, introduced in zip bags and stored for further analyses at normalised lab conditions [28].

\subsection{Physico-chemical characterisation}

\subsubsection{Field Emission Scanning Electron Microscopy (FE-SEM)}

The cryo-fracture surface of the specimens was analysed by means of a Hitachi S-4800 field emission scanning electron microscope (FE-SEM). The samples were cryo-fractured in liquid nitrogen into small pieces, mounted on metal studs and sputtered with a $2 \mathrm{~nm}$ platinum layer using a Cressington 208HR high resolution sputter coater, equipped with a Cressington thickness monitor controller. Then, the samples were saved into a desiccator for $48 \mathrm{~h}$ prior to the analyses. The working conditions in FE-SEM were voltage of $2 \mathrm{kV}$, working distance of $8.4 \mathrm{~mm}$ and magnification $50 \times$.

\subsubsection{Thermogravimetric Analysis (TGA)}

The thermo-oxidative stability was assessed by means of a Mettler-Toledo TGA 851 series. The samples, with a mass of about $4 \mathrm{mg}$, were introduced into $70 \mu \mathrm{L}$ Mettler-Toledo perforated alumina crucibles. Three specimens of each sample were analysed by a dynamic procedure, with 
a heating rate of $10^{\circ} \mathrm{C} \cdot \mathrm{min}^{-1}$ in the temperature range of 25 to $750{ }^{\circ} \mathrm{C}$, under oxidative atmosphere of $\mathrm{O}_{2}$ at a flow rate of $50 \mathrm{~mL} \cdot \mathrm{min}^{-1}$.

\subsubsection{Differential Scanning Calorimetry (DSC)}

The calorimetric data were obtained by differential scanning calorimetry (DSC) by means of a Mettler-Toledo DSC 820 series, equipped with a refrigerated cooling system. The DSC equipment was previously calibrated following the procedure of Indium and Zinc. The samples, with a mass of about $4 \mathrm{mg}$, were placed in $40 \mu \mathrm{L}$ aluminium crucibles. The evaluation of the thermal properties was assessed over linear heating/cooling segments of $10^{\circ} \mathrm{C} \cdot \mathrm{min}^{-1}$ between 0 and $200{ }^{\circ} \mathrm{C}$. All experiments were performed under inert atmosphere of $\mathrm{N}_{2}$ at a flow rate of $50 \mathrm{~mL} \cdot \mathrm{min}^{-1}$. The specimens were characterised in triplicates and the averages of temperatures and enthalpies were taken as representative values.

One of the most representative parameters to ascertain the effect of the degradation in a given polymer is the crystallinity degree $\left(X_{c}\right)$ [29]-[31], which was calculated by means of the Equation 3 ,

$$
X_{c}(\%)=\frac{\left(\Delta h_{m}-\sum \Delta h_{c c}\right)}{A h_{m_{0}}} \times 100 \quad \text { Equation } 3
$$

where $\Delta h_{m}$ is the melting enthalpy of a given sample, $\Delta h_{m 0}$ is the heat of fusion of a $100 \%$ crystalline PLA, and $\Sigma \Delta h_{c c}$ is the summation of enthalpy of all exothermal cold crystallisation

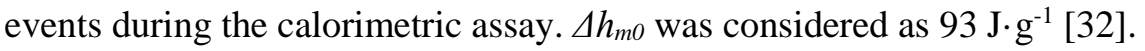

With the purpose of deeply characterise the crystalline structure, the averaged lamellar thicknesses was calculated by applying the Thomson-Gibbs equation (Equation 4), based on the temperatures associated to the melting transitions [33], [34],

$$
l_{C}\left(T_{m}\right)=\left[\left(1-\frac{T_{m}}{T_{m}^{0}}\right) \cdot \frac{\Delta h_{m V}}{2 \cdot \sigma_{e}}\right]^{-1} \quad \text { Equation } 4
$$

where $T_{m}$ is the melting peak temperature; $T_{m}{ }^{0}$ is the equilibrium melting temperature of an infinite crystal $(480 \mathrm{~K}) ; \sigma_{e}$ is the surface free energy of the basal plane where the chains fold $\left(60.89 \cdot 10^{-3}\right.$ $\left.\mathrm{J} \cdot \mathrm{m}^{-2}\right)$; and $\Delta h_{m V}$ is the melting enthalpy per volume unit $\left(111.083 \cdot 10^{8} \mathrm{~J} \cdot \mathrm{m}^{-3}\right)$ [35].

\subsubsection{Size Exclusion Chromatography (SEC)}

Size exclusion chromatography (SEC) was carried out by means of a Malvern Instruments Omnisec Resolve chromatograph. It combined an integrated pump, a degasser, an autosampler and a column oven, along with a Malvern Instruments Omnisec Reveal multi-detector Ultraviolet (UV), Refractive Index (RI), Low and Right Angle Light Scattering (LALS and RALS) and Viscosity (VISC)-. A monodisperse polystyrene standard with $\mathrm{dn} / \mathrm{dc}$ value of 0.185 was used for previous calibration. Two columns from Malvern Instruments (T2000 and T4000) were used $(300 \times 8 \mathrm{~mm})$. Tetrahydrofuran (THF) was used as mobile phase at a flow rate of 1 $\mathrm{mL} \cdot \mathrm{min}^{-1}$ and a column temperature of $35{ }^{\circ} \mathrm{C}$. The samples were dissolved in THF with concentrations of around $2.0 \mathrm{mg} \cdot \mathrm{mL}^{-1}$ and filtered through $0.45 \mu \mathrm{m}$ PTFE filters. Three specimens per sample and two injections per specimen were performed, and the obtained dataa were analysed with the aid of the Omnisec V10 ${ }^{\mathrm{TM}}$ software. 


\section{Results and discussion}

Firstly, a preliminary assessment of the physico-chemical properties of the PLA-based SRCs was performed to set the base scenario for referring further analyses. Subsequently, the biodegradability of these materials was studied when subjected to standard composting conditions according to the ISO 20200. Finally, the effect of the different factors involved in the biodegradation of the composites such as the temperature, the water and the compost was evaluated. For this purpose, the macroscopic and microscopic appearance were assessed, along with the thermo-oxidative stability, the thermal properties and the molar mass of the composites, as a function of the exposure time.

\subsection{Initial physico-chemical assessment of PLA-based SRCs}

The self-reinforced composites as well as the fibre and the matrices were preliminarily evaluated in terms of the macroscopic appearance, the cross-section morphology, the thermal properties, the thermo-oxidative stability and the molar mass, which results are gathered in Figure 1 and Table 3.

a)

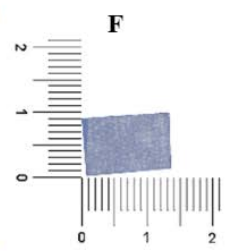

M2

M3

C2
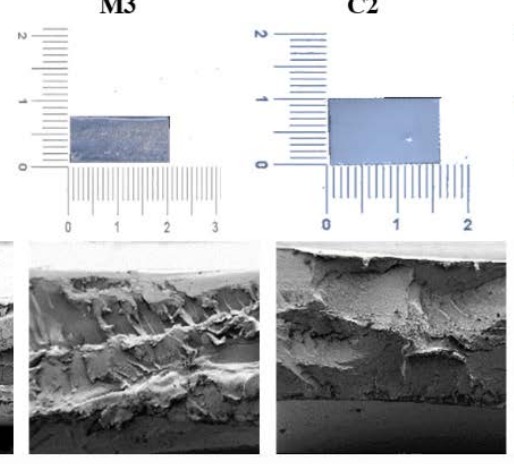

C3

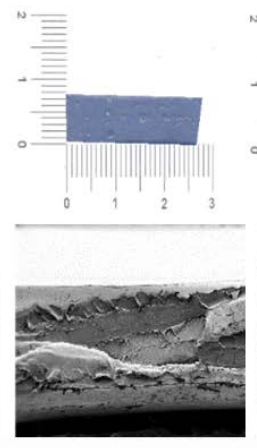

c)
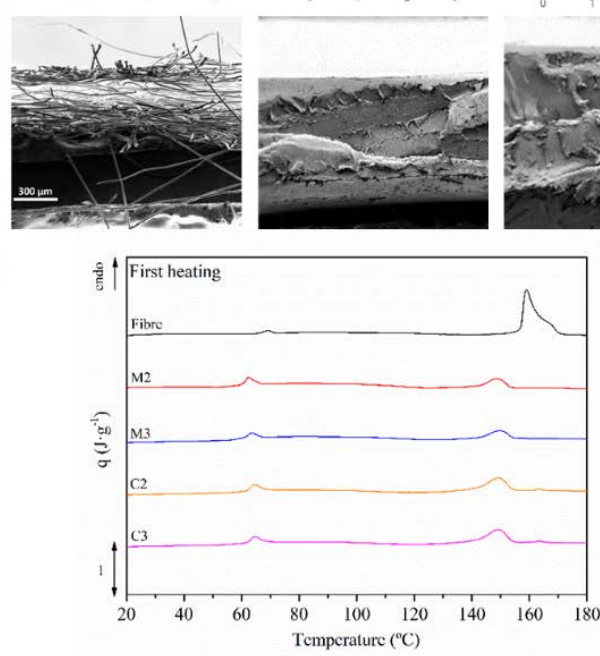

d)

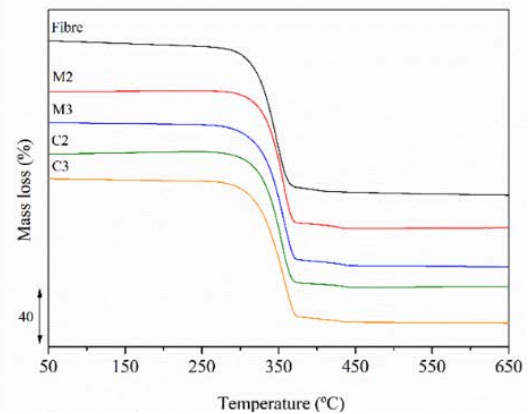

Figure 1. (a) Macroscopic appearance, (b) cross-section morphology (50×), (c) calorimetric thermograms and (d) thermogravimetric curves for fibre, matrices and self-reinforced PLA composites.

The macroscopic appearance shown in Figure 1a could be described as random translucent whitish fibres and translucent matrices and composites. Apparently, processing through thermocompression resulted in a compact structure for matrices and composites. In this sense, fibres and matrices seemed to have physically interacted and outcome in a macroscopically well-processed composite.

The microscopic state, studied by means of the cross-section of the cryo-fractured samples, is represented in Figure 1b. The fibres showed a flat structure, apparently disordered due to the handling of the non-woven mat. The matrices both the M2 and M3 samples seemed to have interacted perfectly, becoming a new single entity. The self-reinforced PLA composites showed 
the fibres completely embedded into the matrices. This fact suggested that the thermocompression procedure was a suitable method to obtain the self-reinforced composites.

The thermal properties and the crystalline morphology were evaluated by differential scanning calorimetry. The thermograms are plotted in Figure 1c and the results, in terms of the enthalpy and temperature associated to the glass transition relaxation $\left(\Delta h_{g-r}, T_{g-r}\right)$, the cold crystallisation $\left(\Delta h_{c c}, T_{c c}\right)$ and the melting $\left(\Delta h_{m}, T_{m}\right)$ as well as the crystallinity degree $\left(X_{c}\right)$, are gathered in Table 3. From the thermograms of the first heating scan, the effect of the processing through thermocompression was assessed. The fibre showed a peak associated to the glass transition around 69 ${ }^{\circ} \mathrm{C}$, followed by a melting process around $160{ }^{\circ} \mathrm{C}$. The highest crystallinity degree was perceived for the fibre, due to the melt spinning processing method, which produced strain-induced crystallinity [36]. The matrices showed a peak associated to the glass transition around $62{ }^{\circ} \mathrm{C}$, followed by a cold-crystallisation around $122^{\circ} \mathrm{C}$ and a melting around $150^{\circ} \mathrm{C}$. For the composites, the low weight fraction of the fibre versus the matrix slightly modified the thermograms. Both matrix and composites showed a crystallinity degree between $2-3 \%$ and revealed that the presence of fibres did not alter the amorphous morphology of the SRCs. In the cooling scan, the glass transition temperature $\left(T_{g}\right)$ was evaluated, which was slightly higher for fibres than for matrices and composites, as suggested in the first heating scan.

The thermo-oxidative stability of the fibre, matrices and self-reinforced composites was evaluated by thermogravimetry. The thermogravimetric curves (TG) plotted in Figure 1d showed three stages of thermal degradation, typical for PLA-based materials [37]-[40]. The first stage, between $60{ }^{\circ} \mathrm{C}$ and $150{ }^{\circ} \mathrm{C}$ with a weight loss of around $1-5 \%$ was attributed to the release of free and bound water. Then, the second stage, between $320^{\circ} \mathrm{C}$ to $375^{\circ} \mathrm{C}$ represented the main degradation process, corresponding to the decomposition of the polymer backbone. Finally, from $380{ }^{\circ} \mathrm{C}$ onwards, the decomposition of char occurred [41], [42]. The mass loss at the end of the assay was almost $100 \%$ for all the studied materials, so the SRCs can be considered as fully thermally decomposable under an oxidative atmosphere. The thermogravimetric curves were characterised in terms of the temperature in which the mass loss was $20 \%\left(T_{20}\right)$; the endset temperature $\left(T_{e}\right)$, calculated by the tangential intercept onto the thermograms after the last mass-loss stage; and the main degradation stage temperature $\left(T_{d}\right)$, as calculated from the peak temperature of the firstorder derivative (DTG) of the TG curves (Table 3). The fibre showed the lowest $T_{20}, T_{e}$ and $T_{d}$, correlated to a slightly lower thermo-oxidative stability due to the high surface-area-to-volume ratio available to the penetration and diffusion of oxygen during decomposition, in contrast to that of the PLA matrix, where only the outer layer was initially liable to the surrounding oxidative medium. Conversely, although no significant differences between matrices and composites were observed, both showed slightly higher thermo-oxidative stability in comparison to that of the fibre. 
Table 3. Thermal properties, thermo-oxidative stability and molar mass results for fibre, matrices and self-reinforced PLA composites. Standard deviation ranged between 1 and 5\%.

\begin{tabular}{|c|c|c|c|c|c|c|c|}
\hline & Parameter & Units & $\mathbf{F}$ & M2 & M3 & $\mathrm{C} 2$ & C3 \\
\hline \multirow{8}{*}{$\begin{array}{l}\text { Thermal } \\
\text { properties }\end{array}$} & $\Delta \boldsymbol{h}_{\boldsymbol{g} \cdot \boldsymbol{r}}$ & $\left(\mathrm{J} \cdot \mathrm{g}^{-1}\right)$ & 1.1 & 3.2 & 3.4 & 3.9 & 3.4 \\
\hline & $T_{g \cdot r}$ & $\left({ }^{\circ} \mathrm{C}\right)$ & 69.1 & 62.5 & 63.3 & 63.5 & 64.5 \\
\hline & $\Delta h_{c c}$ & $\left(J \cdot g^{-1}\right)$ & - & -3.5 & -3.9 & -3.7 & -3.6 \\
\hline & $T_{c c}$ & $\left({ }^{\circ} \mathrm{C}\right)$ & - & 122.1 & 125.5 & 123.6 & 118.3 \\
\hline & $\Delta h_{m}$ & $\left(J \cdot g^{-1}\right)$ & 31.8 & 6.5 & 6.6 & 5.6 & 5.2 \\
\hline & $T_{m}$ & $\left({ }^{\circ} \mathrm{C}\right)$ & 159.3 & 148.4 & 149.4 & 149.4 & 149.1 \\
\hline & $X_{c}$ & (\%) & 34.1 & 3.22 & 2.90 & 2.04 & 55.3 \\
\hline & $T_{g}$ & $\left({ }^{\circ} \mathrm{C}\right)$ & 58.1 & 55.6 & 56.0 & 55.3 & 55.3 \\
\hline \multirow{3}{*}{$\begin{array}{l}\text { Thermo- } \\
\text { oxidative } \\
\text { stability }\end{array}$} & $T_{20}$ & $\left({ }^{\circ} \mathrm{C}\right)$ & 320.7 & 333.6 & 332.4 & 331.5 & 335.4 \\
\hline & $T_{d}$ & $\left({ }^{\circ} \mathrm{C}\right)$ & 346.7 & 357.2 & 356.0 & 355.8 & 356.7 \\
\hline & $T_{e}$ & $\left({ }^{\circ} \mathrm{C}\right)$ & 362.7 & 367.6 & 368.0 & 366.6 & 368.5 \\
\hline \multirow{4}{*}{$\begin{array}{c}\text { Molar } \\
\text { mass }\end{array}$} & $M_{n}$ & $\left(\mathrm{~g} \cdot \mathrm{mol}^{-1}\right)$ & 46640 & 68070 & 70390 & 68490 & 72140 \\
\hline & $M_{w}$ & $\left(\mathrm{~g} \cdot \mathrm{mol}^{-1}\right)$ & 342800 & 122650 & 129240 & 118870 & 124950 \\
\hline & $I V$ & $\left(\mathrm{dL} \cdot \mathrm{g}^{-1}\right)$ & 0.75 & 1.00 & 1.04 & 0.98 & 1.00 \\
\hline & $R h$ & (nm) & 9.99 & 11.99 & 12.34 & 11.81 & 12.06 \\
\hline
\end{tabular}

The molar mass of the prepared materials was evaluated in terms of the average molar mass in number $\left(M_{n}\right)$, the average molar mass in weight $\left(M_{w}\right)$, the intrinsic viscosity $(I V)$ and the hydrodynamic radius $(R h)$, as shown in Table 3. A great difference was observed between fibre and matrices/composites. The fibres showed low molar mass in number, while high molar mass in weight, suggesting high polydispersity. Accordingly, low intrinsic viscosity and hydrodynamic radius was observed. The matrices and composites showed similar results with $M_{n}$ around 70000 $\mathrm{g} \cdot \mathrm{mol}^{-1}$ and $M_{\mathrm{w}}$ around $120000 \mathrm{~g} \cdot \mathrm{mol}^{-1}$, as stated by the manufacturer.

\subsection{Biological degradability of PLA-based self-reinforced composites under the ISO 20200 standard conditions}

According to the preliminary indications of the ISO 20200 [26], a verification procedure of the composting substrate was performed prior to the biological degradation assay. The high temperature and humidity of this standard permits to degrade PLA in a faster way than other burial in soil methodologies [43], [44]. According to the standard, the dry/wet mass relationship was $96.74 \%$, the volatile solids $7.85 \%$, the average $\mathrm{C} / \mathrm{N}$ ratio $32: 1$ and the $\mathrm{pH}$ 6.6. All these parameters were considered suitable for the composting assay according to the standard specifications.

The $\mathrm{pH}$ of each flask along with the dry mass percentage and the absolute volatile solids percentage are gathered in Table 4. Although the $\mathrm{pH}$ was expected to decrease due to the release of lactic acid during the hydrolytic degradation of the polylactide macromolecules [27], [45], the overall $\mathrm{pH}$ increased. This behaviour was related to the release of ammonia and other basic components in the mixture, and the elimination of organic acids by the effect of the microorganisms in the compost medium. Once the biodisintegration assay finished, the volatile solids content of the flasks for F, M2, M3, C2 and C3 increased in 39.8\%, 38.3\%, 40.8\%, 34.8\% and $51.6 \%$, respectively, suggesting that the organic material increased along biodisintegration.

The results of the biodisintegration were validated by means of the decrease in the volatile-solids content $(R)$, as calculated for each flask, and shown in Table 4 . The $R$ can be considered as valid, since all the calculated values of the several flasks were greater than $30 \%$.

The disintegration degree $(D)$ was found higher than $80 \%$ for all cases, within $10 \%$ of difference between specimens for a given sample, as specified in the standard [26]. All these results for the self-reinforced composites were in accordance to the bibliography, when composting neat PLA 
in similar conditions. For instance, Tuominen et al. [46] reported an $80 \%$ of disintegration for PLA prepolymer after 90 days of composting and Kunioka et al. [47] obtained up to $90 \%$ of disintegration of PLA powder after 20 days of exposition to standard composting conditions.

Overall, the self-reinforcing procedure preserved the biodegradability of these materials, and therefore the PLA-based SRCs wastes could be managed and valorised under the same standard composting conditions as PLA.

Table 4. Dry mass percentage, volatile solids and $\mathrm{pH}$ of the synthetic wastes after composting, along with biodisintegration degree $(D)$ and decrease in volatile-solids content $(R)$. Standard deviation between 1 and $5 \%$ was omitted for the sake of clarity.

\begin{tabular}{cccccc}
\hline & $\begin{array}{c}\text { Dry mass } \\
\mathbf{( \% )}\end{array}$ & $\begin{array}{c}\text { VS } \\
\text { (\%wtdry mass) }\end{array}$ & $\mathbf{p H}$ & $\begin{array}{c}\boldsymbol{R} \\
\mathbf{( \% )}\end{array}$ & $\begin{array}{c}\boldsymbol{D} \\
\mathbf{( \% )}\end{array}$ \\
\hline F & 99.02 & 13.04 & 7.34 & 68.02 & 86.35 \\
\hline M2 & 99.12 & 12.71 & 7.21 & 74.61 & 84.54 \\
\hline M3 & 99.34 & 13.26 & 7.33 & 72.48 & 88.83 \\
\hline C2 & 99.36 & 13.43 & 7.58 & 72.79 & 91.29 \\
\hline C3 & 99.23 & 12.04 & 7.42 & 72.20 & 80.49 \\
\hline
\end{tabular}

3.3. Comparison of the biological, hydrothermal and thermal degradation of PLA-based selfreinforced composites

Along with the biodegradation procedure under compost, parallel hydrothermal and thermal degradation procedures were simultaneously performed, in order to ascertain the effect of each parameter, i.e. humidity and temperature, and merely temperature, respectively, on the degradation of self-reinforced composites. The differences between the effects of each factor during the degradation were evaluated in terms of macroscopic appearance, cross-section morphology, thermal properties, thermo-oxidative stability and molar mass. For the sake of conciseness, the results in this section were particularly evaluated for the SRCs C2 and C3, while the results for M2 and M3 can be found in the Supplementary Material.

\subsubsection{Disintegration: macroscopic appearance}

The macroscopic appearance along the different stages during the biological, hydrothermal and thermal degradation procedures was assessed. The pictures of the SRCs as a function of the exposure time are gathered in Figure 2. As observed, the composites were disintegrated both under biological and hydrothermal degrading conditions, while those subjected to thermal degradation remained apparently unaffected. Biodegradation showed the highest degree of disintegration, which was ascribed to the effect of microorganisms in the composting substrate. The hydrothermal conditions promoted a similar but delayed disintegration behaviour in the composites. The presumably hydrolytic scission of the ester bond of the PLA molecules due to the effect of both the water and the temperature may have promoted disintegration. However, along the thermal degradation, the macroscopic appearance of the samples remained unchanged, since the temperature was not high enough itself to promote significant structural changes as those reported at high temperatures [18].

\subsubsection{Cross-section morphology: microscopic appearance}

The changes in the microscopic appearance of the cross-section morphology caused by the different degradation procedures were monitored. The surface of the cryo-fractured SRCs along the biological, hydrothermal and thermal degradation are shown in Figure 3. Similarly to what was observed at macroscopic level, the microscopic observation of the interface between the 
matrix and the fibre showed the strongest degradation after composting, followed by the hydrothermal and thermal degradation, respectively. Indeed, the composites showed no apparent changes after being subjected to thermal degradation.

When subjected to biological and hydrothermal degradation, a smooth surface was observed due to the synergistic effect of compost, water and temperature, which promoted the reorganisation of the polymer chains [48]. These samples showed a more fragile fracture as degradation time increased, possibly due to the increased crystallinity in the samples. Water seemed to diffuse into the SRCs, resulting in a global swelling that increased their thickness. Moreover, the swelling of fibres in the composites may cause the generation of small cracks in the fibre-matrix interface, providing alternative paths for water to diffuse, resulting in a higher hydrolysis degree [41].

However, when subjected to thermal degradation, the SRCs seemed to maintain their initial morphology along the assay. In spite of following the same cryo-fracture procedure as done with all the samples, they still showed a ductile behaviour. Moreover, the structures of the fibre and the matrix into the composite could be well differentiated and remained apparently unchanged regardless the time of exposition. 


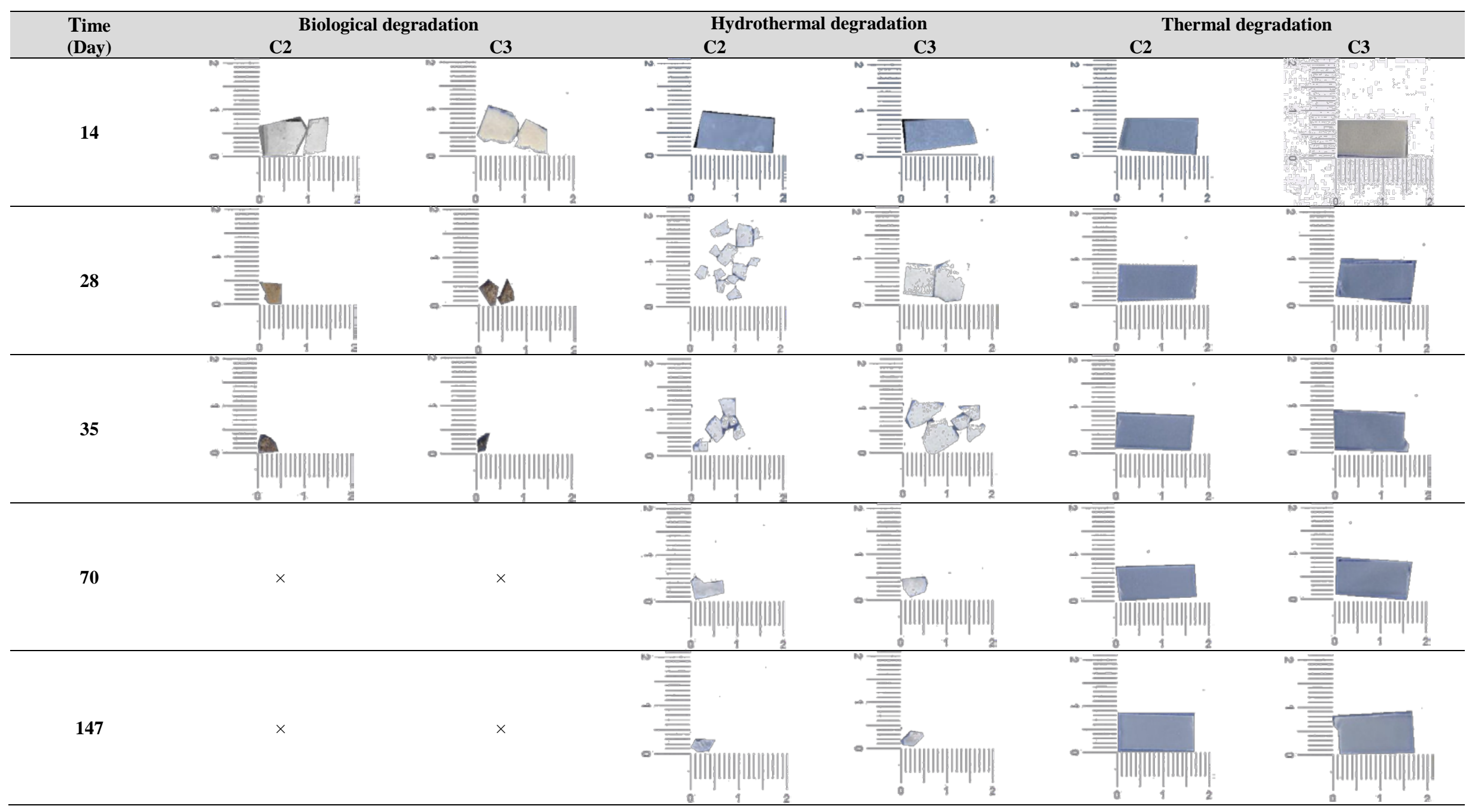

Figure 2. Macroscopic appearance of the C2 and C3 self-reinforced composites along the biological, hydrothermal and thermal degradation. The macroscopic appearance of the fibre, M2 and M3 can be found in the Supplementary Material. 


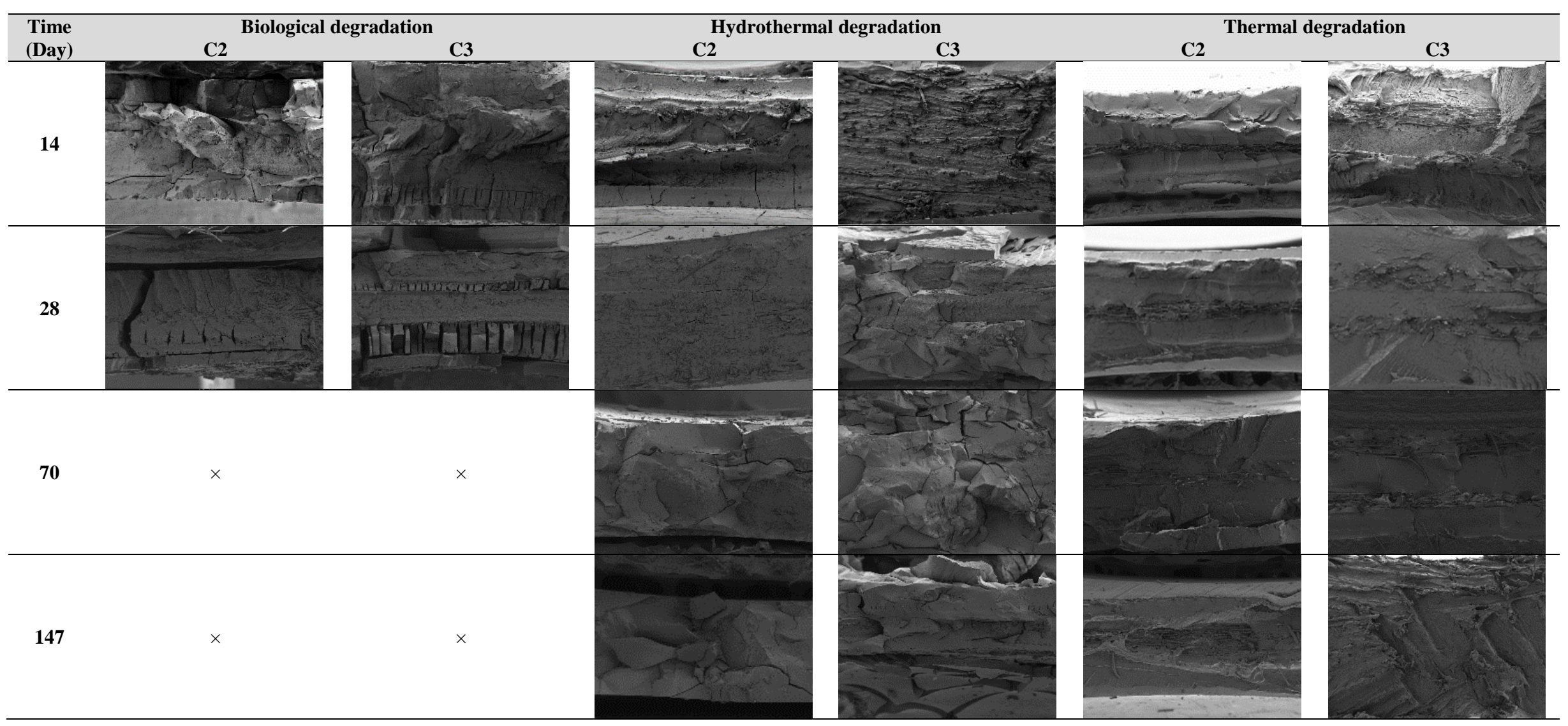

Figure 3. Cross-section morphology of the C2 and C3 self-reinforced composites along the biological, hydrothermal and thermal degradation. The microscopic appearance of the fibre, M2 and M3 can be found in the Supplementary Material. 


\subsubsection{Thermo-oxidative stability}

The structural changes promoted by the biological, hydrothermal and thermal degradation were monitored in terms of the thermo-oxidative stability. Figure 4 displays the thermogravimetric curves for the C2 and C3 SRCs subjected to the different degradation procedures. The profiles in this study revealed few low mass-loss stages below $250^{\circ} \mathrm{C}$. It was indicative of the decomposition of weakened molten macromolecular chains of PLA, which length had been reduced by the degradation processes. This fact was more relevant for PLA subjected to biological and hydrothermal degradation. In order to quantify the stability of the composites, these curves were characterised in terms of the temperature at which a mass-loss of $20 \%$ was reached $\left(T_{20}\right)$, the main degradation temperature $\left(T_{d}\right)$ and the endset temperature $\left(T_{e}\right)$, which results are gathered in Table 5.
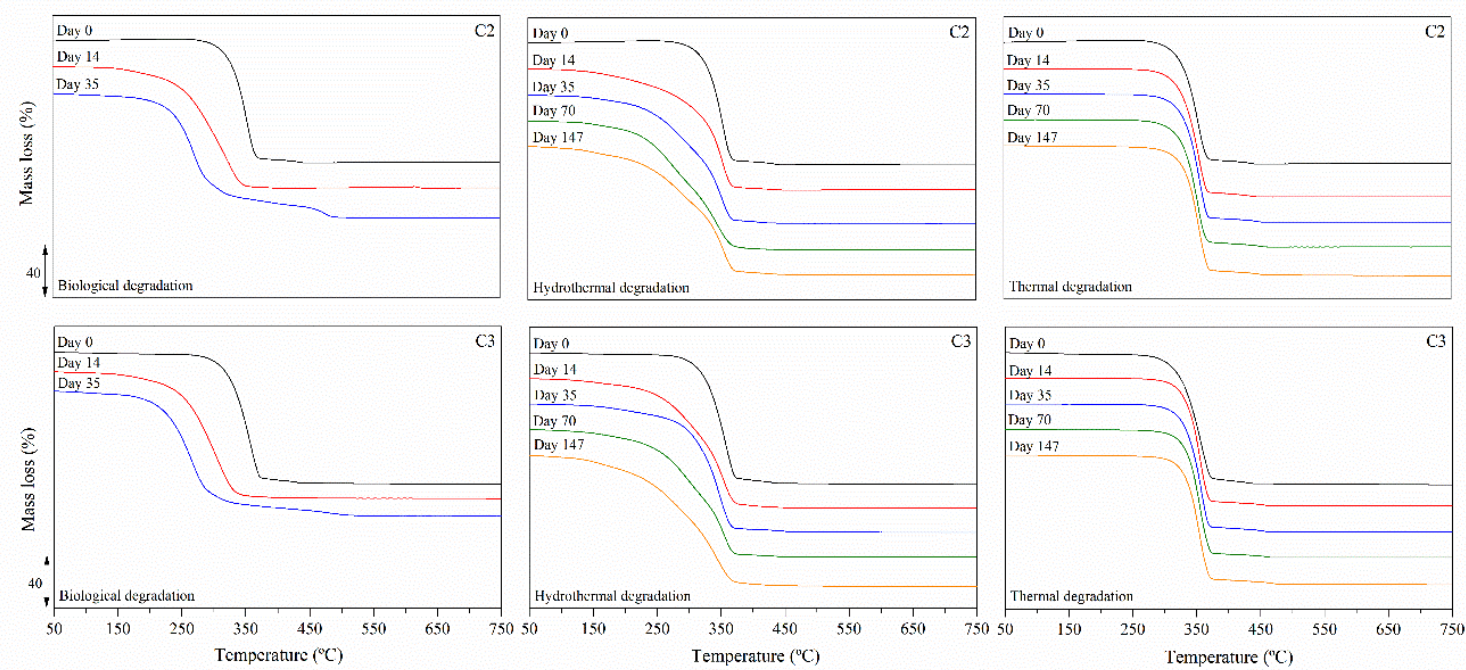

Figure 4. Thermogravimetric curves for the C2 and C3 self-reinforced composites along the biological, hydrothermal and thermal degradation. Thermogravimetric curves for the fibre, M2 and M3 are plotted in the Supplementary Material.

In particular, the SRCs subjected to biological degradation revealed a general displacement of the curve towards lower temperatures, traduced in a lower thermo-oxidative stability as a function of the exposition time, correlated to the advance of degradation.

The effect of the hydrothermal conditions was similar to that of the biological assay. However, in this case the analysis could suitably be performed until the last stages of immersion. The original double stage decomposition turned into a multi-decomposition profile. The initial amorphous morphology of the SRCs permitted the extended hydrolytic degradation in bulk along immersion in water, which produced a general decrease of the thermo-oxidative stability.

The thermal degradation was revealed as the less aggressive degrading procedure, in comparison to the biological and hydrothermal degradation. In addition, no significant differences were found between matrices and composites. As can be seen in Table 5, the $T_{20}, T_{d}$ and $T_{e}$ showed similar values along the assay, which allows to suggest that the performance of the SRCs under these thermal conditions would be similar to that of neat PLA. That is, the fabrication of PLA-PLA composites preserved the thermo-oxidative stability of PLA. 
Table 5. Thermo-oxidative 20\% decomposition ( $\left.T_{20}\right)$, main degradation $\left(T_{d}\right)$ and endset $\left(T_{e}\right)$ temperatures for the C2 and C3 self-reinforced composites along the biological, hydrothermal and thermal degradation.

\begin{tabular}{|c|c|c|c|c|c|c|c|}
\hline & \multicolumn{4}{|c|}{$\mathrm{C} 2$} & \multicolumn{3}{|c|}{ C3 } \\
\hline & $\begin{array}{l}\text { Time } \\
\text { (Day) }\end{array}$ & $\begin{array}{l}\mathrm{T}_{20} \\
\left({ }^{\circ} \mathrm{C}\right)\end{array}$ & $\begin{array}{c}T_{d} \\
\left({ }^{\circ} \mathrm{C}\right)\end{array}$ & $\begin{array}{c}T_{e} \\
\left({ }^{\circ} \mathrm{C}\right)\end{array}$ & $\begin{array}{c}\mathrm{T}_{20} \\
\left({ }^{\circ} \mathrm{C}\right)\end{array}$ & $\begin{array}{c}T_{d} \\
\left({ }^{\circ} \mathrm{C}\right)\end{array}$ & $\begin{array}{c}T_{e} \\
\left({ }^{\circ} \mathrm{C}\right)\end{array}$ \\
\hline \multirow{3}{*}{$\begin{array}{c}\text { Biological } \\
\text { degradation }\end{array}$} & 0 & $331.5 \pm 1.6$ & $355.8 \pm 1.7$ & $366.6 \pm 0.4$ & $335.4 \pm 1.6$ & $356.7 \pm 0.2$ & $368.5 \pm 1.4$ \\
\hline & 14 & $252.1 \pm 1.4$ & $324.3 \pm 0.6$ & $350.0 \pm 1.8$ & $250.0 \pm 1.4$ & $303.0 \pm 1.5$ & $320.4 \pm 1.6$ \\
\hline & 35 & $239.4 \pm 1.2$ & $270.6 \pm 1.3$ & $308.7 \pm 1.5$ & $226.4 \pm 1.1$ & $266.3 \pm 1.8$ & $298.9 \pm 0.5$ \\
\hline \multirow{5}{*}{$\begin{array}{c}\text { Hydrothermal } \\
\text { degradation }\end{array}$} & 0 & $331.5 \pm 1.6$ & $355.8 \pm 1.7$ & $366.6 \pm 0.4$ & $335.4 \pm 1.6$ & $356.7 \pm 0.2$ & $368.5 \pm 1.4$ \\
\hline & 14 & $313.9 \pm 1.2$ & $351.1 \pm 1.4$ & $365.9 \pm 1.2$ & $310.7 \pm 0.8$ & $350.8 \pm 1.1$ & $366.3 \pm 1.5$ \\
\hline & 35 & $297.4 \pm 0.4$ & $350.9 \pm 0.4$ & $365.1 \pm 0.9$ & $298.0 \pm 0.7$ & $350.6 \pm 1.0$ & $364.9 \pm 0.9$ \\
\hline & 70 & $296.1 \pm 1.8$ & $345.9 \pm 0.8$ & $365.0 \pm 0.5$ & $291.4 \pm 1.5$ & $345.6 \pm 0.5$ & $362.9 \pm 1.3$ \\
\hline & 147 & $292.7 \pm 1.1$ & $278.5 \pm 2.4$ & $341.4 \pm 1.4$ & $290.2 \pm 2.1$ & $280.5 \pm 1.5$ & $332.6 \pm 1.8$ \\
\hline \multirow{5}{*}{$\begin{array}{c}\text { Thermal } \\
\text { degradation }\end{array}$} & 0 & $331.5 \pm 1.6$ & $355.8 \pm 1.7$ & $366.6 \pm 0.4$ & $335.4 \pm 1.6$ & $356.7 \pm 0.2$ & $368.5 \pm 1.4$ \\
\hline & 14 & $328.1 \pm 1.2$ & $355.3 \pm 0.6$ & $367.3 \pm 0.6$ & $333.6 \pm 1.3$ & $354.9 \pm 0.5$ & $367.2 \pm 1.0$ \\
\hline & 35 & $331.8 \pm 1.5$ & $356.4 \pm 1.2$ & $367.9 \pm 0.8$ & $332.6 \pm 0.8$ & $355.1 \pm 0.3$ & $367.7 \pm 0.5$ \\
\hline & 70 & $329.6 \pm 0.9$ & $353.4 \pm 0.8$ & $366.8 \pm 0.9$ & $335.6 \pm 1.8$ & $354.5 \pm 0.8$ & $368.6 \pm 1.1$ \\
\hline & 147 & $330.9 \pm 0.8$ & $354.4 \pm 1.4$ & $367.9 \pm 0.4$ & $333.9 \pm 1.2$ & $353.4 \pm 0.3$ & $367.8 \pm 0.4$ \\
\hline
\end{tabular}

\subsubsection{Thermal properties and crystallinity}

The thermal properties and the crystalline morphology of the SRCs exposed to biological, hydrothermal and thermal degradation were monitored by differential scanning calorimetry (DSC) [49]-[55]. The calorimetric thermograms of the first heating scan are shown in Figure 5. The analysis was performed in terms of structural relaxation associated to the glass transition, cold crystallisation and melting from the first heating scan, while the glass transition was evaluated from the cooling scan.
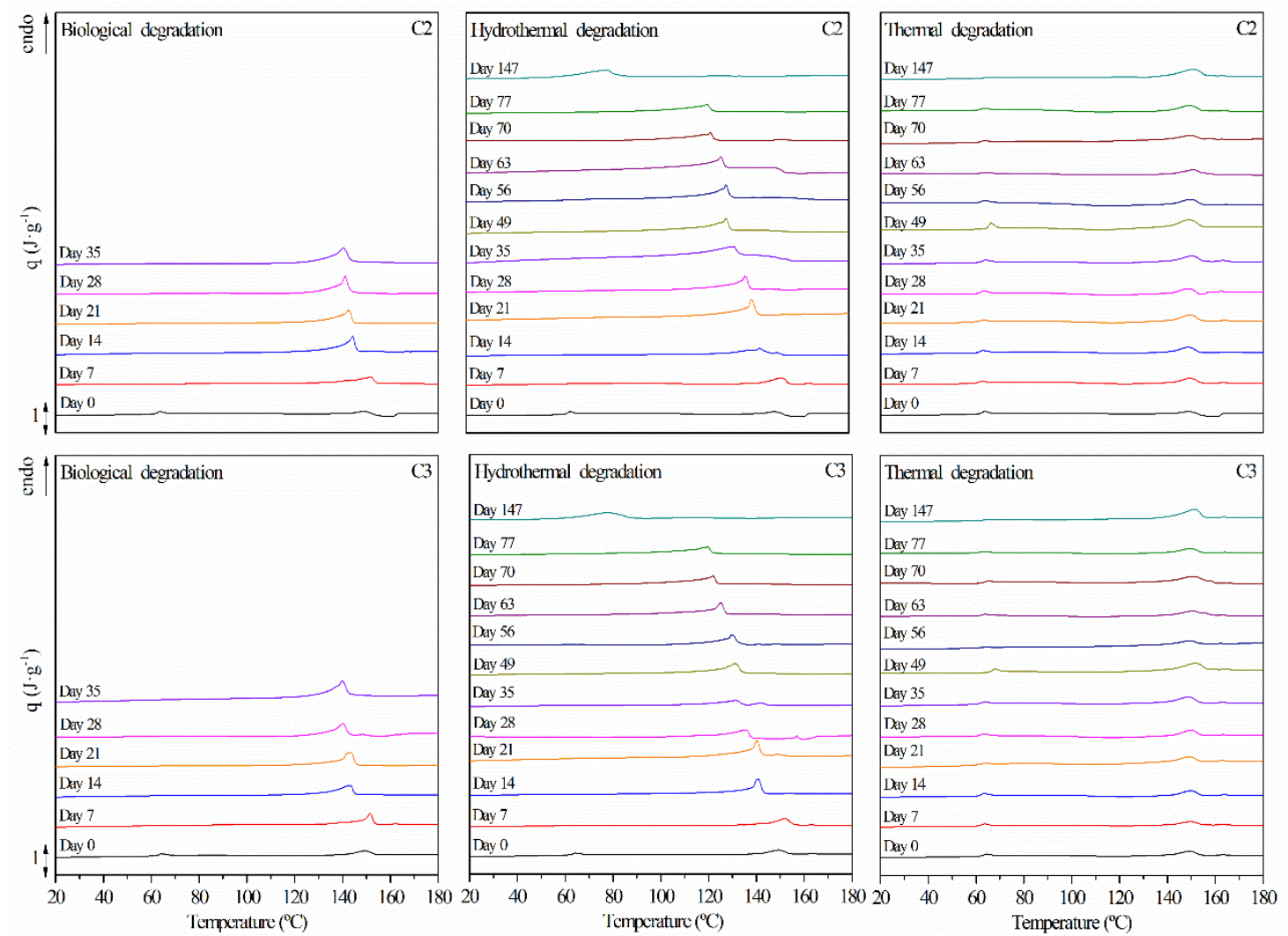

Figure 5. First heating calorimetric thermograms for the C2 and C3 self-reinforced composites along the biological, hydrothermal and thermal degradation. The thermograms for the fibre, M2 and M3 are plotted in the Supplementary Material. 
The samples subjected to biological and hydrothermal degradation showed a similar behaviour. However, the tendency of those biologically degraded was less representative due to the heterogeneity in the degradation process, as well as to the high rate of disintegration of the samples.

A general overview of the first heating scan showed a global decrease of the structural relaxation temperature $\left(T_{g-r}\right)$ and enthalpy $\left(\Delta h_{g-r}\right)$. The structural relaxation is closely related to the glass transition and occurs when the samples are heated above the $T_{g}$ after annealing in the glassy state [56]-[60]. Due to the proximity of the temperature of the degradation assay $\left(58^{\circ} \mathrm{C}\right.$ ) to the $T_{g}$ of PLA $\left(55-60^{\circ} \mathrm{C}\right)$, the polymer chains seemed to have moved and flowed during the degradation. Indeed, the $T_{g}$ showed a decrease of $\sim 10^{\circ} \mathrm{C}$ along the biological and hydrothermal degradation, as gathered in Table 6. A diminution of the $\Delta h_{g-r}$ over time was found, which indicated the plasticising effect of water [48], [51]. Moreover, the decrease of the $T_{g-r}$ could be ascribed to the chain scission phenomenon caused by the effect of water and compost, which resulted in shorter polymer chains with higher ability to move and flow at lower temperatures [51], [61].

Table 6. Glass transition temperature $\left(T_{g}\right)$ for the C2 and C3 self-reinforced composites along the biological, hydrothermal and thermal degradation.

\begin{tabular}{|c|c|c|c|c|}
\hline & \multirow{3}{*}{$\begin{array}{l}\text { Time } \\
\text { (Day) }\end{array}$} & \multicolumn{3}{|c|}{$T_{g}$} \\
\hline & & \multicolumn{3}{|c|}{$\left({ }^{\circ} \mathrm{C}\right)$} \\
\hline & & Biological & Hydrothermal & Thermal \\
\hline \multirow{12}{*}{$\mathrm{C} 2$} & 0 & $55.3 \pm 0.2$ & $55.30 \pm 0.16$ & $55.3 \pm 0.2$ \\
\hline & 7 & $54.0 \pm 0.9$ & $55.11 \pm 1.25$ & $55.9 \pm 1.0$ \\
\hline & 14 & $45.8 \pm 0.9$ & $45.42 \pm 0.4$ & $55.3 \pm 1.4$ \\
\hline & 21 & $43.2 \pm 1.7$ & $45.72 \pm 0.2$ & $54.6 \pm 0.6$ \\
\hline & 28 & $44.3 \pm 4.8$ & $45.34 \pm 1.4$ & $55.6 \pm 0.2$ \\
\hline & 35 & $32.6 \pm 0.3$ & $46.81 \pm 2.1$ & $55.6 \pm 0.2$ \\
\hline & 49 & - & $41.46 \pm 0.3$ & $55.5 \pm 1.7$ \\
\hline & 56 & - & $41.57 \pm 0.7$ & $55.1 \pm 0.2$ \\
\hline & 63 & - & $40.79 \pm 0.1$ & $55.8 \pm 0.2$ \\
\hline & 70 & - & $39.47 \pm 0.9$ & $57.5 \pm 0.1$ \\
\hline & 77 & - & $39.17 \pm 0.7$ & $55.3 \pm 0.3$ \\
\hline & 147 & - & $30.29 \pm 0.1$ & $54.6 \pm 1.6$ \\
\hline \multirow{12}{*}{ C3 } & 0 & $55.3 \pm 0.1$ & $55.29 \pm 0.1$ & $55.3 \pm 0.1$ \\
\hline & 7 & $53.9 \pm 1.4$ & $55.09 \pm 0.3$ & $54.7 \pm 0.4$ \\
\hline & 14 & $46.6 \pm 0.6$ & $43.80 \pm 0.1$ & $55.6 \pm 0.7$ \\
\hline & 20 & $44.3 \pm 1.8$ & $45.23 \pm 0.8$ & $54.0 \pm 0.6$ \\
\hline & 28 & $37.9 \pm 1.2$ & $25.53 \pm 0.1$ & $55.7 \pm 0.9$ \\
\hline & 35 & $39.0 \pm 0.3$ & $40.82 \pm 0.2$ & $59.2 \pm 0.9$ \\
\hline & 49 & - & $40.59 \pm 0.2$ & $55.8 \pm 1.7$ \\
\hline & 56 & - & $43.27 \pm 0.2$ & $55.0 \pm 0.2$ \\
\hline & 63 & - & $39.33 \pm 0.5$ & $56.9 \pm 0.1$ \\
\hline & 70 & - & $39.97 \pm 0.2$ & $53.3 \pm 1.7$ \\
\hline & 77 & - & $39.12 \pm 0.6$ & $53.7 \pm 0.6$ \\
\hline & 147 & - & $34.78 \pm 0.1$ & $54.5 \pm 1.6$ \\
\hline
\end{tabular}

Concerning the cold-crystallisation phenomenon, its enthalpy $\left(\Delta h_{c c 1}\right)$ and peak temperature $\left(T_{c c 1}\right)$ were evaluated. This event moved to lower temperatures until it completely disappeared, becoming unperceivable for degraded samples. The disappearance of the cold crystallisation during the calorimetric analysis is related to the crystallisation of the amorphous phase along the biological and hydrothermal degrading assays, respectively [62]. Because of the development of crystallinity during degradation, the melting enthalpy $\left(\Delta h_{m}\right)$ and the subsequent crystallinity degree $\left(X_{c}\right)$ increased. The melting temperature $\left(T_{m}\right)$ is closely related to crystallite size, by means of the lamellar thickness $\left(l_{c}\right)$ of the crystalline structure [52], [63], [64]. Accordingly, a lower $T_{m}$ would suggest the melting of smaller crystals. Indeed, as new crystals melted at lower 
temperatures, newer lower crystallite size were expected for the degraded samples. Figure 6 shows the evolution of the $X_{c}$ and $l_{c}$ as a function of the exposure time.

Overall, crystallisation was developed along the biological and hydrothermal degradation processes. The compost, water and temperature acted as a driving force to enhance polymer degradation and reduce the chain lengths of the PLA that boosted their mobility to form new crystalline structures [51]. Nevertheless, after long exposure time, more than 70 days, a decrease of the crystallinity degree was found. Once the amorphous regions were severely degraded, the water seemed to have diffused into the crystalline domains, hydrolytically reacted and reduced the global crystallinity of the samples until they were entirely collapsed and disintegrated.

The SRCs subjected to thermal degradation showed a different behaviour and the changes were less perceivable. The structural relaxation was almost unaffected along the thermal degradation, as corroborated by the glass transition temperature obtained in the cooling scan. Then, the cold crystallisation slightly moved towards lower temperatures, and the melting temperature and enthalpy marginally increased. This observation can be attributed to a slightly increase in the crystallinity degree $\left(X_{c}\right)$ and maintenance of the lamellar thickness $\left(l_{c}\right)$ of the existing crystalline domains along the degradation, as plotted in Figure 6. Merely temperature affected the material in a slower rate than combined water and temperature -and compost-. To perceive such a considerable change in the thermal properties due to the effect of the thermal degradation, longer or more severe exposition to these conditions would have been required [62].
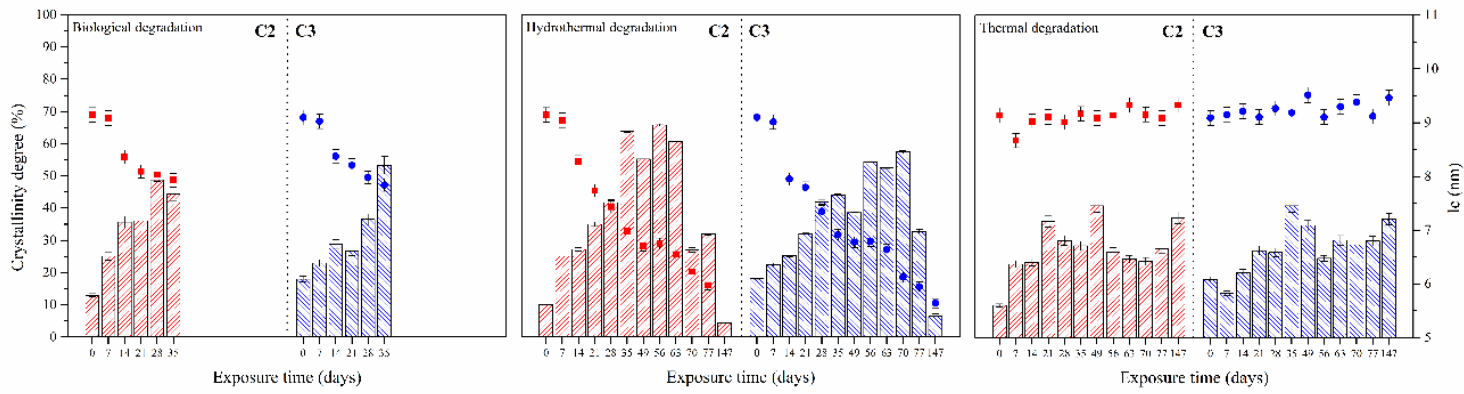

Figure 6. Crystallinity degree $\left(X_{c}\right)$-bars- and lamellar thickness $\left(l_{c}\right)$-scatter- evolution for the C2 and C3 self-reinforced composites along the biological, hydrothermal and thermal degradation.

\subsubsection{Molar mass}

The changes in the molar mass promoted by the biological, hydrothermal and thermal degradation were evaluated to corroborate the chain scission phenomenon suggested in the previous sections and to model the degradation process. The obtained average molar mass in number $\left(M_{n}\right)$ of the SRCs is plotted in Figure 7 as a function of the exposure time. As expected, a general decrease of the $M_{n}$ was found for all degrading conditions, but accelerated for the biological and hydrothermal degradations.

Some authors have described the biological, hydrothermal and thermal degradation of PLA as random chain scission reactions, associated with first and second order processes [42], [62], [65], [66]. Indeed, fitting the obtained experimental data to these models may help to describe the degradation behaviour of the SRCs. 

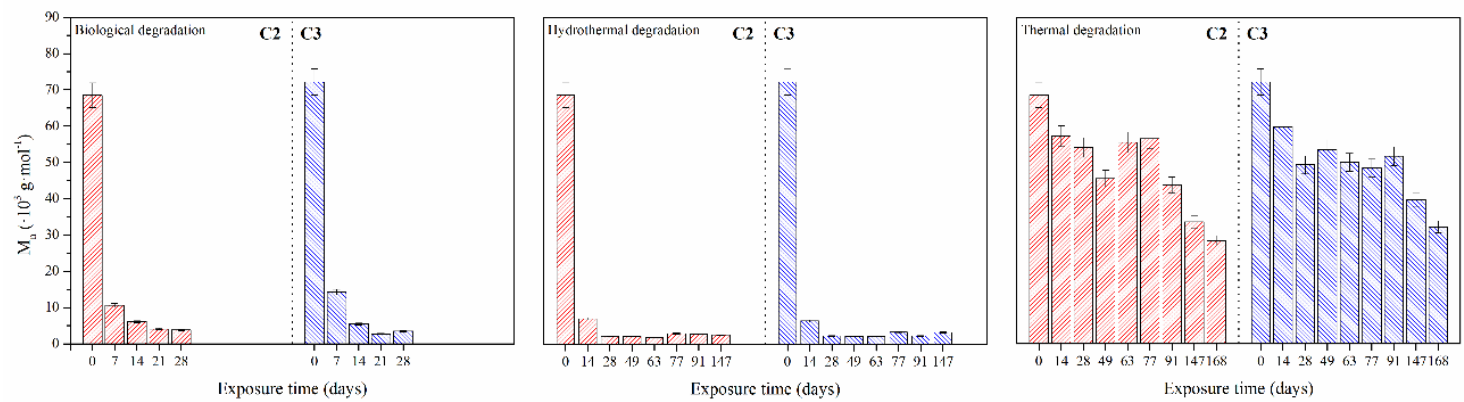

Figure 7. Average molar mass in number $\left(M_{n}\right)$ for the C2 and C3 self-reinforced composites along the biological, hydrothermal and thermal degradation. Values for the fibre, M2 and M3 are gathered in the

\section{Supplementary Material.}

Materials exposed to biological and hydrothermal degradation were fast degraded in the early stage and $M_{n}$ tended to decrease slowly thereafter. Certainly, the degradation of the SRCs was not linearly dependent on the time of exposition [62]. These results were fitted to a first order rate law according to the expression gathered in Table 7, to define the degradation model. The high rate of degradation ( $k$ ) found is known to highly depend on the temperature and water to which the samples are exposed, especially if temperature is above the glass transition of the polymer [67]. The biodegradation of SRCs may follow the two-step process defined for PLA. First, chain scission through hydrolytic breakage takes place and then, the enzymatic reaction by which low molar mass compounds are assimilated by microorganisms, ultimately leading to carbon dioxide and water occurs [68], [69]. When immersed in water, the reaction of hydrolysis of PLA was faster and the hydrolytic degradation results in products of lower molar mass. The highest degradation rate during the first stage of immersion was due to a greater activity of water molecules as compared to the equilibrium state [70], [71]. A statistical chain breakage of the ester bond in the PLA and a depolymerisation process are the mechanisms which could result from that irreversible chemical degradation [72], [73]. Moreover, the fibre swelling in composites may cause delamination and generation of micro-cracks in the fibre-matrix interface providing the penetration of water into the whole composite, promoting higher hydrolysis degree.

Table 7. Fitting model and parameters for the modelling of the average molar mass in number $\left(M_{n}\right)$ for the C2 and C3 self-reinforced composites along the biological, hydrothermal and thermal degradation.

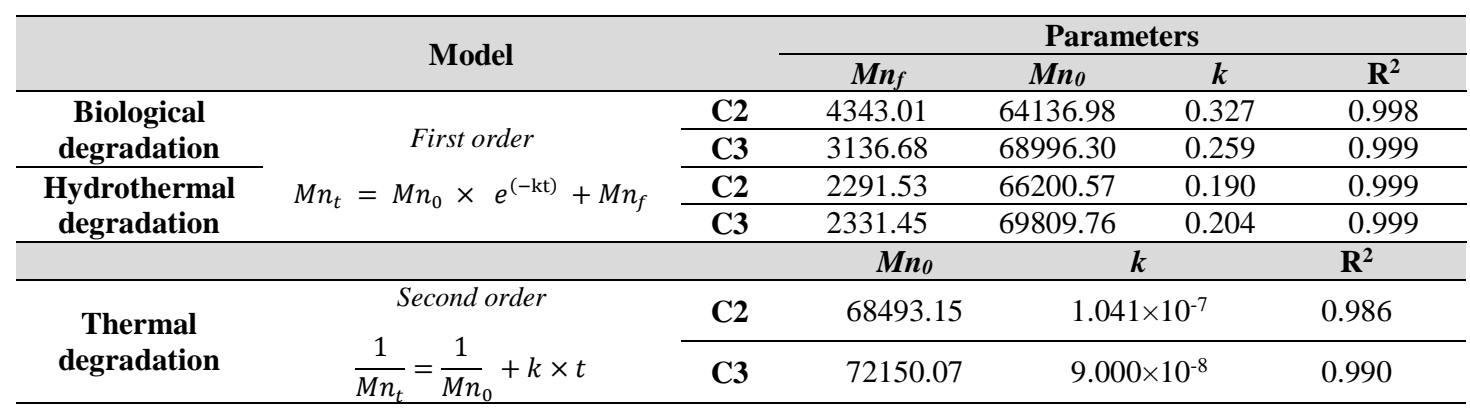

When subjected to thermal degradation, a more progressive decrease of the $M_{n}$ as a function of time was found, reaching almost the $50 \%$ of the initial value, as suggested for the lower rate of degradation $(k)$. The slower decrease of the molar mass in comparison to that found due to the biological and hydrothermal degradations can be attributed to the absence of ester bond hydrolysis caused by compost and water, respectively. Prior works describe the thermal degradation of PLA as a second order decay law [62], [65], [74], which expression and parameters are gathered in 
Table 7. According to the bibliography, a thermo-oxidative random scission of the ester bond seem to be the major degradation mechanism when subjected to the effect of temperature [62].

\section{Conclusions}

Self-reinforced composites (SRCs) based in PLA were suitably obtained through a thermocompression procedure. The composites were translucent with a compact structure, in which the fibres were embedded into the matrices.

In order to evaluate the influence of temperature, water and compost on the biodegradation of the SRCs, three parallel thermal, hydrothermal and biological degradation assays were performed. Although degradation was perceived due to the effect of temperature, the synergistic combination of temperature, water and compost was found to be critical in the biodegradation of these materials.

Whilst SRCs subjected to thermal degradation slightly developed crystallinity and showed an unaltered macroscopic appearance, water and temperature acted as a driving force to highly develop crystallinity as a function of the exposure time when subjected to hydrothermal and biological degradation. Moreover, the hydrolytic degradation promoted erosion and deterioration and even disintegration at the end of the assay. Finally, the effect of the compost along with water and temperature were revealed as the most aggressive conditions. There, the combination of hydrolysis of high molar mass molecules and biological assimilation of monomers and oligomers collapsed the self-reinforced composites in a short period of time.

Overall, the self-reinforcing procedure did not restrict the biodegradability of these materials, and therefore the PLA-based SRCs wastes could be managed and valorised under the same standard composting conditions as PLA.

\section{Acknowledgements}

$\mathrm{PhD}$ Vera Realinho and PhD M ${ }^{\mathrm{a}}$ Lluisa Maspoch at the Centre Català del Plàstic (Terrasa, Spain) are acknowledged for their grateful collaboration in the preparation of the PLA film. The authors would like to thank the support of the European Regional Development Fund and the Spanish Ministry of Economy and Competitiveness, through the Research Projects ENE2014-53734-C21-R and UPOV13-3E-1947. The Spanish Ministry of Education, Culture and Sports is also thanked for the FPU grant for O. Gil-Castell (FPU13/01916). Generalitat Valenciana is recognised for the APOSTD14/041 program for J.D. Badia. IESMAT S.A. and Malvern Instruments Ltd. are recognised for their grateful collaboration.

\section{Bibliography}

[1] M. Tolinski, "Towards a Peaceful Coexistence between Bio-based and Fossil Fuel-based Plastics," in Plastics and Sustainability, John Wiley \& Sons, Inc., 2011, pp. i-xv.

[2] J. D. Badia, O. Gil-Castell, and A. Ribes-Greus, "Long-term properties and end-of-life of polymers from renewable resources,” Polym. Degrad. Stab., vol. 137, pp. 35-57, 2017.

[3] J. P. Greene, “Sustainable Plastic Products,” in Sustainable Plastics, John Wiley \& Sons, Inc., 2014, pp. 145186.

[4] J. D. Badia, E. Strömberg, T. Kittikorn, M. Ek, S. Karlsson, and A. Ribes-Greus, "Relevant factors for the eco-design of polylactide/sisal biocomposites to control biodegradation in soil in an end-of-life scenario," Polym. Degrad. Stab., vol. 143, pp. 9-19, Sep. 2017.

[5] E. Farrington DW et al. Poly (lactic acid) fibres. In: Blackburn RS, "Biodegradable and sustainable fibres.," Cambridae Woodhead Publ. Ltd., pp. 191-220, 2005.

[6] et al. Henton D, Gruber P, "Polylactic acid technology. Natural fibres, biopolymer, and biocomposites," pp. 
527-79, 2005.

[7] O. M., “Chemical syntheses of biodegradable polymers.,” Prog Polym Sci, vol. 27, pp. 87-133, 2002.

[8] S. S. Auras R, Harte B, R. Auras, B. Harte, and S. Selke, “An overview of polylactides as packaging materials,” vol. 4, no. 9, 2004.

[9] S. Domenek, S. Fernandes-Nassar, and V. Ducruet, "Rheology, Mechanical Properties, and Barrier Properties of Poly(lactic acid)," in Synthesis, Structure and Properties of Poly(lactic acid), M. L. Di Lorenzo and R. Androsch, Eds. Cham: Springer International Publishing, 2018, pp. 303-341.

[10] L. L. et Al., "Mechanical properties of poly (butylene succinate) (PBS) biocomposites reinforced with surface modified jute fibre," Compos. Part A, vol. 40, pp. 669-74, 2009.

[11] X. Li, C. L. Chu, L. Liu, X. K. Liu, J. Bai, C. Guo, F. Xue, P. H. Lin, and P. K. Chu, "Biodegradable polylactic acid based-composite reinforced unidirectionally with high-strength magnesium alloy wires," Biomaterials, vol. 49, pp. 135-144, 2015.

[12] Moliner C., J. D. Badia, B. Bosio, A. Arato, A. Lagazzo, M. Capurro, and A. Ribes-Greus, "Mechanical and thermal performance of PLA and PHBV-based biopolymers as potential alternatives to PET," Chem. Eng. Trans. 57, vol. 57, pp. 1417-1422, 2017.

[13] J. D. Badia, P. Reig-Rodrigo, R. Teruel-Juanes, T. Kittikorn, E. Strömberg, M. Ek, S. Karlsson, and A. RibesGreus, "Effect of sisal and hydrothermal ageing on the dielectric behaviour of polylactide/sisal biocomposites,” Compos. Sci. Technol., vol. 149, pp. 1-10, 2017.

[14] P. R. Capiati NJ, “The concept of one polymer composites modelled with high density polyethylene,” J Mater Sci, vol. 10, no. 10, pp. 1671-1677, 1975.

[15] N.-M. Barkoula, T. Peijs, T. Schimanski, and J. Loos, "Processing of single polymer composites using the concept of constrained fibers,” Polym. Compos., vol. 26, no. 1, pp. 114-120, 2005.

[16] W. Jia, R. H. Gong, and P. J. Hogg, "Poly (lactic acid) fibre reinforced biodegradable composites," Compos. Part B Eng., vol. 62, pp. 104-112, 2014.

[17] J. M. Zhang and T. Peijs, "Self-reinforced poly(ethylene terephthalate) composites by hot consolidation of Bicomponent PET yarns,” Compos. Part A Appl. Sci. Manuf., vol. 41, no. 8, pp. 964-972, 2010.

[18] J. D. Badia and A. Ribes-Greus, "Mechanical recycling of polylactide, upgrading trends and combination of valorization techniques,” Eur. Polym. J., vol. 84, pp. 22-39, 2016.

[19] F. Mai, W. Tu, E. Bilotti, and T. Peijs, "Preparation and properties of self-reinforced poly(lactic acid) composites based on oriented tapes,” Compos. Part A Appl. Sci. Manuf., vol. 76, pp. 145-153, 2015.

[20] P. T. Cabrera NO, Alcock B, Loos J, "Processing of all-polypropylene composites for ultimate recyclability,” Proc Inst Mech Eng L J Mater Des Appl, vol. 218, no. 2, pp. 145-155, 2004.

[21] P. T. Alcock B, “Technology and development of self-reinforced polymer composites,” Springer, 2013.

[22] T. P, “Bioabsorbable surgical composite materials,” Adv Mater, vol. 4, no. 9, pp. 589-591, 1992.

[23] M. Kellomäki, H. Niiranen, K. Puumanen, N. Ashammakhi, T. Waris, and P. Törmälä, "Bioabsorbable scaffolds for guided bone regeneration and generation,” Biomaterials, vol. 21, no. 24, pp. 2495-2505, 2000.

[24] C. Guo, L. Zhou, and J. Lv, "Effects of expandable graphite and modified ammonium polyphosphate on the flame-retardant and mechanical properties of wood flour-polypropylene composites,” Polym. Polym. Compos., vol. 21, no. 7, pp. 449-456, 2013.

[25] O. Gil-Castell, J. D. Badia, and A. Ribes-Greus, "Suitability of blends from virgin and reprocessed polylactide: performance and energy valorisation kinetics,” Accept. Publ. J. Renew. Mater., 2017.

[26] "ISO20200:2004 Plastics - Determination of the degree of disintegration of plastic materials under simulated composting conditions in a laboratory-scale test."

[27] Ghorpade, V.M., Gennadios, A., Hanna, M.A., "Laboratory composting of extruded poly (lactic acid) sheets,” vol. 76, no. 1, pp. 57-61, 2001.

[28] “ISO291. Plastics. Standard atmospheres for conditioning and testing.” 1997.

[29] G. Gorrasi and R. Pantani, "Effect of PLA grades and morphologies on hydrolytic degradation at composting temperature: Assessment of structural modification and kinetic parameters,” Polym. Degrad. Stab., vol. 98, no. 5, 2013.

[30] L. C. E. Struik, “The mechanical and physical ageing of semicrystalline polymers: 1,” Polymer (Guildf)., vol. 28, no. 9, pp. 1521-1533, 1987.

[31] O. Gil-Castell, J. D. D. Badia, E. Strömberg, S. Karlsson, and A. Ribes-Greus, "Effect of the dissolution time into an acid hydrolytic solvent to tailor electrospun nanofibrous polycaprolactone scaffolds,” Eur. Polym. J., vol. 87, pp. 174-187, 2017.

[32] W. G. Fischer E. W., Sterzel H. J., E. W. Fischer, H. J. Sterzel, and G. Wegner, "Investigation of the structure of solution grown crystals of lactide copolymers by means of chemical reactions," Kolloid-Zeitschrift Zeitschrift f??r Polym., vol. 251, no. 11, pp. 980-990, 1973.

[33] J. I. Lauritzen and J. D. Hoffman, "Formation of Polymer Crystals with Folded Chains from Dilute Solution,” J. Chem. Phys., vol. 31, no. 6, pp. 1680-1681, 1959. 
[34] J. D. Hoffman and J. I. Lauritzen, "Crystallization of Bulk Polymers With Chain Folding: Theory of Growth of Lamellar Spherulites,” J. Res. Natl. Bur. Stand. - A. Phys. Chem., vol. 65, no. August, p. 1961, 1961.

[35] R. Vasanthakumari and A. J. Pennings, “Crystallization kinetics of poly(l-lactic acid),” Polymer (Guildf)., vol. 24, no. 2, pp. 175-178, 1983.

[36] J. A. Cicero and J. R. Dorgan, "Physical Properties and Fiber Morphology of Poly(lactic acid) Obtained from Continuous Two-Step Melt Spinning,” J. Polym. Environ., vol. 9, no. 1, pp. 1-10, 2001.

[37] M. P. Arrieta, J. López, E. Rayón, and A. Jiménez, "Disintegrability under composting conditions of plasticized PLA-PHB blends,” 2014.

[38] M. J. Bajpai PK, Singh I, “Tribological behaviour of natural fiber reinforced PLA composites.,” Wear 2012.

[39] A. Awal, M. Rana, and M. Sain, "Thermorheological and mechanical properties of cellulose reinforced PLA bio-composites,” Mech. Mater., vol. 80, no. Part A, pp. 87-95, 2015.

[40] J. D. Badia, L. Santonja-Blasco, A. Martínez-Felipe, and A. Ribes-Greus, “A methodology to assess the energetic valorization of bio-based polymers from the packaging industry: pyrolysis of reprocessed polylactide.,” Bioresour. Technol., vol. 111, pp. 468-75, May 2012.

[41] O. Gil-Castell, J. D. D. Badia, T. Kittikorn, E. Strömberg, M. Ek, S. Karlsson, A. Ribes-Greus, E. Strömberg, M. Ek, S. Karlsson, and A. Ribes-Greus, "Impact of hydrothermal ageing on the thermal stability, morphology and viscoelastic performance of PLA/sisal biocomposites,” Polym. Degrad. Stab., vol. 132, pp. 87-96, Mar. 2016.

[42] J. D. Badia, L. Santonja-Blasco, A. Martí-nez-Felipe, A. Ribes-Greus, A. Martínez-Felipe, and A. RibesGreus, "Reprocessed polylactide: studies of thermo-oxidative decomposition.," Bioresour. Technol., vol. 114, no. 0, pp. 622-8, Jun. 2012.

[43] J. D. Badía, R. Moriana, L. Santonja-Blasco, and A. Ribes-Greus, "A thermogravimetric approach to study the influence of a biodegradation in soil test to a Poly(lactic acid),” Macromol. Symp., 2008.

[44] L. Santonja-Blasco, R. Moriana, J. D. Badía, and A. Ribes-Greus, "Thermal analysis applied to the characterization of degradation in soil of polylactide: I. Calorimetric and viscoelastic analyses,” Polym. Degrad. Stab., vol. 95, no. 11, pp. 2185-2191, Nov. 2010.

[45] J. Tuominen, J., Kylma, J., Kapanen, A., Venelampi, O., Itavaara, M., Seppala, "Biodegradation of lactic acid based polymers under controlled composting conditions and evaluation of the ecotoxicological impact.," Biomacromolecules, no. 3, pp. 445-455, 2002.

[46] J. Tuominen, J., Kylma, J., Kapanen, A., Venelampi, O., Itavaara, M., Seppala, "Biodegradation of lactic acid based polymers under controlled composting conditions and evaluation of the ecotoxicological impact," Biomacromolecules, vol. 3, p. 445-455., 2002.

[47] M. Kunioka, F. Ninomiya, M. Funabashi, and 2006. Kunioka, M., Ninomiya, F., Funabashi, M., "Biodegradation of poly(lactic acid) powders proposed as the reference test materials for the international standard of biodegradation evaluation methods,” Polym. Degrad. Stab., vol. 91, no. 9, pp. 1919-1928, Sep. 2006.

[48] O. Gil-Castell, J. D. D. Badia, T. Kittikorn, E. Strömberg, A. Martínez-Felipe, M. Ek, S. Karlsson, and A. Ribes-Greus, "Hydrothermal ageing of polylactide/sisal biocomposites. Studies of water absorption behaviour and Physico-Chemical performance,” Polym. Degrad. Stab., vol. 108, pp. 212-222, Oct. 2014.

[49] Z. Xiong, Y. Yang, J. Feng, X. Zhang, C. Zhang, Z. Tang, and J. Zhu, "Preparation and characterization of poly(lactic acid)/starch composites toughened with epoxidized soybean oil.,” Carbohydr. Polym., vol. 92, no. 1, pp. 810-6, Jan. 2013.

[50] Y. Dong, A. Ghataura, H. Takagi, H. J. Haroosh, A. N. Nakagaito, and K. T. Lau, "Polylactic acid (PLA) biocomposites reinforced with coir fibres: Evaluation of mechanical performance and multifunctional properties," Compos. Part A Appl. Sci. Manuf., vol. 63, pp. 76-84, 2014.

[51] J. D. Badia, L. Santonja-Blasco, A. Martínez-Felipe, and A. Ribes-Greus, "Hygrothermal ageing of reprocessed polylactide,” Polym. Degrad. Stab., vol. 97, no. 10, pp. 1881-1890, Oct. 2012.

[52] J. D. Badia, E. Strömberg, S. Karlsson, and A. Ribes-Greus, "The role of crystalline, mobile amorphous and rigid amorphous fractions in the performance of recycled poly (ethylene terephthalate) (PET),” Polym. Degrad. Stab., vol. 97, no. 1, pp. 98-107, Jan. 2012.

[53] J. D. Badia, E. Strömberg, S. Karlsson, and A. Ribes-Greus, "Material valorisation of amorphous polylactide. Influence of thermo-mechanical degradation on the morphology, segmental dynamics, thermal and mechanical performance,” Polym. Degrad. Stab., vol. 97, no. 4, pp. 670-678, Apr. 2012.

[54] J. D. Badia, F. Vilaplana, S. Karlsson, and A. Ribes-Greus, "Thermal analysis as a quality tool for assessing the influence of thermo-mechanical degradation on recycled poly(ethylene terephthalate)," Polym. Test., vol. 28, no. 2, pp. 169-175, 2009.

[55] O. Gil-Castell, J. D. Badia, I. Ontoria-Oviedo, D. Castellano, B. Marco, A. Rabal, J. J. Bou, A. Serra, L. Monreal, M. Blanes, P. Sepúlveda, and A. Ribes-Greus, "In vitro validation of biomedical polyester-based scaffolds: Poly(lactide- co -glycolide) as model-case,” Polym. Test., Apr. 2018.

[56] Kovacs AJ, "Transition vitreuse dans les polymeres amorphes: etude phenomenologique Fortschr," Hochpolym-Forsch, vol. 3, pp. 394-507, 1963. 
[57] N. M. Goldstein M, "Volume relaxation in zinc chloride glass,” Phys Chem Glas., vol. 6, pp. 6-126, 1965.

[58] S. S. Suga H, "Thermodynamic investigation on glassy states of pure simple compounds," J. Non-Cryst. Solids, no. 16, pp. 171-194, 1974.

[59] Y. H., "Enthalpy relaxation of polymeric glasses,” Netsu-Sokutei, vol. 13, pp. 191-199, 1986.

[60] Y. H., "Relationship between enthalpy relaxation and dynamic mechanical relaxation of engineering plastics," Thermochim Acta, no. 266, pp. 199-127, 1995.

[61] K. T. Yoshii T, Yoshida H, "Effect of structural relaxation of glassy PET on crystallization process observed by the simultaneous DSC-XRD and DSC-FTIR,” Thermochim Acta, no. 431, pp. 177-181, 2005.

[62] L. Santonja-Blasco, A. Ribes-Greus, and R. G. Alamo, "Comparative thermal, biological and photodegradation kinetics of polylactide and effect on crystallization rates,” Polym. Degrad. Stab., vol. 98, no. 3, pp. 771-784, Mar. 2013.

[63] M. L, “Crystallization of Polymers,” Cambridge Univ. Press, vol. 2, 2002.

[64] H. Li and M. A. Huneault, "Effect of nucleation and plasticization on the crystallization of poly(lactic acid)," Polymer (Guildf)., vol. 48, no. 23, pp. 6855-6866, 2007.

[65] Y. Aoyagi, K. Yamashita, and Y. Doi, "Thermal degradation of poly[(R)-3-hydroxybutyrate], poly[عcaprolactone], and poly[(S)-lactide],” Polym. Degrad. Stab., vol. 76, no. 1, pp. 53-59, Jan. 2002.

[66] X. Liu, Y. Zou, W. Li, G. Cao, and W. Chen, "Kinetics of thermo-oxidative and thermal degradation of poly(d,l-lactide) (PDLLA) at processing temperature,” Polym. Degrad. Stab., vol. 91, no. 12, pp. 3259-3265, 2006.

[67] A.-F. F. Mohd-Adnan, H. Nishida, and Y. Shirai, "Evaluation of kinetics parameters for poly(l-lactic acid) hydrolysis under high-pressure steam,” Polym. Degrad. Stab., vol. 93, no. 6, pp. 1053-1058, Jun. 2008.

[68] G. Kale, R. Auras, S. P. Singh, and R. Narayan, "Biodegradability of polylactide bottles in real and simulated composting conditions,” Polym. Test., vol. 26, no. 8, pp. 1049-1061, Dec. 2007.

[69] V. M. Torres A, Li S M, Roussos S, "Poly (lactic acid) degradation in soil or under controlled composting and ambient expossure conditions,” J Appl Polym Sci, vol. 62, no. 13, pp. 2295-2302, 1996.

[70] P. C. G. Shah S.S., Zhu K.J., "Poly-DL-lactic acid: Polyethylene glycol block copolymers. The influence of polyethylene glycol on the degradation of poly-DL-lactic acid,” 2012.

[71] C. Way, K. Dean, D. Y. Wu, and E. Palombo, "Biodegradation of sequentially surface treated lignocellulose reinforced polylactic acid composites: Carbon dioxide evolution and morphology,” Polym. Degrad. Stab., vol. 97, no. 3, pp. 430-438, Mar. 2012.

[72] M. P. Foulc, A. Bergeret, L. Ferry, P. Ienny, and A. Crespy, "Study of hygrothermal ageing of glass fibre reinforced PET composites,” vol. 89, pp. 461-470, 2005.

[73] F. Carrasco, P. Pagès, J. Gámez-Pérez, O. O. Santana, and M. L. Maspoch, "Processing of poly(lactic acid): Characterization of chemical structure, thermal stability and mechanical properties,” Polym. Degrad. Stab., vol. 95, no. 2, pp. 116-125, Feb. 2010.

[74] I. C. McNeill and H. A. Leiper, "Degradation studies of some polyesters and polycarbonates—2. Polylactide: Degradation under isothermal conditions, thermal degradation mechanism and photolysis of the polymer," Polym. Degrad. Stab., vol. 11, no. 4, pp. 309-326, Jan. 1985. 